\title{
Research on the Cultivation of High School Students' Computational Thinking Based on DBR Strategy
}

\author{
MA Xiu-lin, SU You-yuan, LIANG Jing \\ Beijing Normal University, Beijing, China
}

\begin{abstract}
In the digital age, computing thinking has become the core content of information literacy for middle school students, how to implement the strategic goal of developing middle school students' computational thinking is the key problem of middle school information technology curriculum construction. Starting from the definition and dimension of computational thinking and the characteristics of information technology courses, we discussed the feasibility of cultivating students' computational thinking in the course of information technology, and explored the convergence point between various dimensions of computational thinking and high school information technology courses, as well as the training strategy of computational thinking. Based on the characteristics and internal rules of the course "application of multimedia technology" in the course of information technology, we put forward the idea of integrating "abstract, modeling, decomposition, and synthesis" into the Photoshop (PS) module, cultivated students' computational thinking in the work design, and guided the teachers' teaching activities and students' work design with the research paradigm of design-based research (DBR), in order to enable students gradually form a deep quality of computational thinking. This study was conducted among 112 students in the second year of senior high school affiliated to Renmin University of China and involved three rounds of teaching practice. This study verified the feasibility of developing high school students' computational thinking based on information technology courses and DBR model, and formed a teaching model of cultivating high school students' computational thinking based on information technology course.
\end{abstract}

Keywords: computational thinking, high school students, information technology courses, design, DBR

\section{Introduction}

\section{The Emergence of the Concept of Computational Thinking and Its Value to Personnel Training}

The greatest contribution of computer science and technology to human beings lies in its ability to influence people's actions, thoughts, and methods in production, work, study, and life. The ideological basis of realizing this intention is not a narrow instrumental theory, nor is it a simple technicism, but rather influences people's ways of solving problems from the level of thinking mode. The methodological value of computer science has prompted people to rethink the role of computer in scientific research, education, life, and entertainment, and promoted the concept of "computational thinking" (Ma, Wu, \& Liu, 2015).

High School Information Technology Curriculum Standard Revised (Chinese) in 2016 also pointed out

MA Xiu-lin, Ph.D., associate professor, School of Educational Technology, Beijing Normal University. SU You-yuan, master degree candidate, School of Educational Technology, Beijing Normal University. LIANG Jing, master degree candidate, School of Educational Technology, Beijing Normal University. 
that the core literacy elements of information technology disciplines are: information consciousness, computational thinking, digital learning and innovation, and information social responsibility. The training objectives of high school information technology course is to make students learn to use computational thinking for problem identification, analysis, abstract, modeling, and design system solutions, form pluralistic understanding of human beings and the world in the process of digital learning, and become qualified citizens in digital age (Ren \& Huang, 2016).

The core aim of high school information technology education is to cultivate students' personality quality and key ability to adapt to the personal lifelong development and social development, among which the most important is students' ability to solve problems with information technology in complex situations (Xie, 2017).

\section{The Definition and Connotation of Computational Thinking}

In March 2006, Professor Zhou of Carnegie Mellon University proposed the concept of computational thinking in Communications of the ACM, an authoritative journal of computer science in the United States. Professor Zhou thought that computational thinking is a series of thinking activity covered the breadth of computer science by using the basic concept of the computer science "solving problem, designing system, and understanding human behavior" (Wing, 2006). In 2011, Professor Zhou redefined computational thinking. She thought that computational thinking is a thinking process of solving the problem; it can express problems and solutions clearly and abstractly in ways that information processing agents (machines or people) can effectively perform (Wing, 2011). Academician Chen pointed out that when computational thinking is truly integrated into the whole of human activities, it serves as an effective tool for solving problems, which should be mastered by everyone and used everywhere (Chen \& Dong, 2011). The cultivation of the computational thinking mainly included eight aspects: computing, abstract, automation, design, communication, coordination, memory, and evaluation (Zhang, Guo, \& Li, 2015).

The definition of computational thinking does not form a unified definition, but scholars' opinion of elements is consistent. In summary, it mainly includes abstraction, generalization, decomposition, algorithm, debugging, and other elements (Angeli et al., 2016).

\section{High School Students' Problems in the Development of Computational Thinking}

Although computational thinking is very important for the development of personal ability of high school students, most of the students are still seriously lacking in computational thinking and ability. And establishing special training courses for the training of computational thinking is difficult. On the one hand, teaching the concepts, rules, and connotations of computational thinking in the form of pure theoretical courses only encourages students to recite and memorize abstract concepts related to computational thinking, and cannot truly realize deep understanding and mastery. On the other hand, it is the mainstream idea of education to let primary and middle school students reduce their burden and give them more free time. It is not a good choice to cultivate students' computational thinking by increasing class hours.

Through what means and strategies, how to improve students' computational thinking consciousness, methods, and ability, and achieve education and cultivation of computational thinking has become a necessary problem in the training of middle school talents. 


\section{Research Questions}

From the perspective of international exploration experience, computational thinking is integrated into students' knowledge learning and problem-solving process through multi-disciplinary integration, so as to cultivate students' computational thinking (Chen, Huang, \& Liang, 2018). It is the general practice.

Most of the information technology curriculum content is based on the computer and network technology, which already contains the principle and ideas of computational thinking. Therefore, integrating the cultivation of computational thinking into the information technology curriculum and then enabling students to master the theory, strategy, and technology of computational thinking is feasible.

This study is to use high school information technology courses, to explore the problems of computational thinking training for students in high school, and to explore the integrating point and cultivating strategies of high school information technology course and computational thinking. The specific problems of this study include the following aspects:

1. This study aims to train high school students in what aspects of computational thinking;

2. What is the convergence point of the computational thinking dimension to be cultivated and the information technology course?

3. What strategies should be adopted in the process of computational thinking training and how effective is it?

\section{Research Plan}

\section{Establish Dimensions and the Convergence Point}

Establish the training dimensions of computational thinking. The nature of the computational thinking is abstraction and automation in information age, which transforms the real problem into computing problems that can be solved by the computer ( $\mathrm{Li} \& \mathrm{Gao}, 2017$ ), its goal is to problem-solving and the core strategy is to "modeling", namely, abstraction, modeling in dealing with the social reality.

Considering the learners' characteristics, the comprehension ability and training needs of high school students, this study decided to choose high school students' abstraction, modeling, analysis, and synthesis, a total of four dimensions as the main dimensions and primary target of computational thinking training.

Establish the convergence point between the training dimension and the information technology course. In the age of big data, the importance of computational thinking is self-evident, but in high school, it is not suitable to offer a simple course of "cultivation of computational thinking". If establishing the computational thinking training course independently, on the one hand, it is easy to put the curriculum into the theory of "cramming" type and does not comply with the nature of "computing thinking should be related closely practical problems". On the other hand, it will also occupy students' limited hours, which is not in line with education's goal of "reducing the burden".

The general process of design is to find and identify problems, analyze problems, design schemes, make models, test, evaluate, and optimize. The core of design ability is analysis and synthesis, and ultimately, it is the ability of analysis and abstraction of real problems, which coincides with the dimension of computational thinking.

Through the analysis of high school general technical textbooks, we found that many design-related modules or chapters are involved. Therefore, with the help of some modules or chapters in the course of 
information technology, it is feasible in theory to integrate the cultivation of computational thinking into the process of design of the work, so as to cultivate students' design ability and computational thinking.

\section{Establish Training Strategy and Teaching Design}

Establish the training mode of computational thinking based on "design". The cultivation of the computational thinking cannot use "engage in idle theorizing" type to recite absolutely. It should put the related dimensions of computational thinking connotation into the special module of information technology course, and let the student's computational thinking level develop imperceptibly in the process of learning information technology knowledge and mastering certain skills of information technology. Therefore, this study introduced the computational thinking training strategy based on "design".

Establish design-based research (DBR) as the core of the calculation thinking training strategy. The teaching process includes teachers' teaching and students' learning. For students, they should cultivate and improve their design ability in the information technology course and pay attention to the design process of their works. For teachers, they need to carefully design teaching content and teaching links to promote the development of students' design ability, computational thinking ability, and teachers' teaching ability. In this process, both the development of students' design ability and the teaching design carried out by teachers to achieve this goal are a process of discovering and improving problems in practice.

DBR is a kind of system and flexible methodology, its purpose is in the real situation, based on researchers and practitioners of collaboration, through the repeated cycle of analysis, design, development, and implementation, to improve the education practice and refine the design principles and theories of context sensitive (Jiao, 2008). It overcomes the disconnection between theory and practice in China's education research, the single research process and the fact that the research results have no practical value. There are mainly theoretical, practical, and interventionist orientations about DBR at present. This research is based on the education intervention orientation of Zhang and Liu (2007).

This study mainly includes two levels of DBR. On the one hand, students need to complete the design of their works carefully according to the course objectives and learning rules in the process of learning information technology knowledge. Then, with the iterative design process, students' works are constantly optimized and improved, which is a DBR process. Through the process of iteration, promote learners' gradual improvement of abstract, modeling, analysis, and comprehensive, and eventually achieve the training goal of "strengthening the consciousness computational thinking, mastering the method of computational thinking, and improving the ability of computational thinking". On the other hand, the teaching design of teachers is also a DBR process. Teachers' teaching design should follow the DBR theory and grow in design and continuous iteration and optimization.

Teaching activity design oriented to "design". Based on the general process and necessary factors of teaching design, and the general process of designing, the teaching activities of teachers are completed. On the basis of clarifying the computational thinking contained in the chapter content and completing the design of teaching content, the teacher adopts the following strategies to organize teaching activities:

1. Teachers should encourage students to think about how to computerize practical problems and form abstract and modeling ideas. In teaching, teachers not only need to explain the course content and specific steps to complete tasks, but also need to explain the process of transforming from a real problem to a computer operable model. They should present their thoughts on the design of the work and the journey from the design 
goal to the final work, in order to encourage students to think about how to abstract and model complex problems in the real society step by step and realize them by computer.

Only when teachers consciously present the "design" thinking mode in the teaching process and guide students step by step can students gradually form the habit of solving problems with "computer modeling" and improve their thinking ability.

2. Task-based teaching focuses on learners' learning, emphases that learners' learning process must be combined with learning tasks, and stimulates and maintain learners' interest and motivation in learning by completing tasks (Mou, Tan, \& Zhou, 2011). In teaching, teachers should use task-driven method and integrate the thinking mode of task decomposition and synthesis.

This study uses task-driven teaching method to carry out teaching through "task decomposition, task design, task reflection, and task optimization". Students will enhance the training of computational thinking in the process of design, problem-solving, and task completion.

Learning activities design oriented to "design". According to the general process of design, students are required to follow the general process of "clear objectives, task decomposition, and abstract modeling" to complete the design. This process mainly includes the following steps:

1. Define the task;

2. Analyze the task theme, and decompose the consolidated task into several manageable sub-tasks;

3. Ask students to think about how to implement each subtask computerized, and form a technical scheme with operability in the field of computer technology;

4. In view of the plan that has been formed and according to the key points of course, students have to think about what they want to do, how to do it, what they need to prepare, and what they need to pay attention to;

5. Collect the relevant materials, design and produce the works, and record the work design report timely

6. In the process of designing works, teachers should give real-time guidance, advocate mutual help with other students.

Layout design task to all students and organize the students to carry out the work of design activity. In the process of students' work design, teachers should rectify the students' adverse phenomenon "light design, heavy operation" in common, and more attention should be paid to solve the frequent phenomenon of "free riding" in team collaboration.

\section{Manage and Monitor the Thought Formation Process}

Students are required to submit design reports. The formation process of work design report is a procedural learning record. It is a process of "abstraction" and "modeling", which can reflect the formation process of students' thinking. At the same time, through the work design report, students can have a clearer understanding of the design idea and process of the work. Teachers can understand students' thinking process, grasp the students' problems in time, and carry out specific guidance on time. This forms a diversified evaluation method. The specific work design report is shown in Table 1.

Include the design report into the work quality evaluation standard. Teachers' evaluation of students' works is not limited to the presentation of the final results of design works, but also includes the report of the design process of works, which is regarded as an important factor to measure the quality of works. Through the work design report, teachers can judge the students' thinking mode, the process of thinking formation, and 
changes in computational thinking consciousness, method, and ability. This is the important basis for evaluating whether students improve their computational thinking. Concrete evaluation standard is shown in Table 2.

Table 1

Work Design Report

\begin{tabular}{|l|l|}
\hline The name of the work & \\
\hline Author & \\
\hline Sources of creativity & \\
\hline Design ideas & \\
\hline Specific production process & \\
\hline Harvest & \\
\hline
\end{tabular}

Table 2

Work Quality Evaluation Criteria

\begin{tabular}{|l|l|}
\hline The evaluation index & Requirements and scores \\
\hline \multirow{2}{*}{ Work content } & Outstanding theme (10) \\
\cline { 2 - 2 } & Beautiful and harmonious design and complete composition (10) \\
\hline Creativity & Novel form and clever design (10) \\
\hline Technicality & Correct and flexible use of course content (20) \\
\hline Computational thinking & Clear thinking, smooth logic, and efficient problem-solving, etc. (50) \\
\hline
\end{tabular}

\section{Computational Thinking Level Questionnaire}

Besides measuring the development level of students' computational thinking according to the integrity of the design report and the quality of the work, it is also necessary to carry out quantitative measurement of students' computational thinking consciousness, method, and ability by means of questionnaire.

The measurement of the development level of computational thinking usually focuses on the three dimensions: computational thinking consciousness, computational thinking method, and computational thinking ability. On the basis of referring to the computational thinking assessment scale at home and abroad, this study combined with the content of information technology courses in senior high school, and designed the "middle school students' computational thinking development level questionnaire", in order to understand more objectively and accurately whether the students' computational thinking has changed before and after the course.

The questionnaire designed 14 questions from three dimensions of computational thinking consciousness, method, and ability. Specifically, there were five questions for computational thinking consciousness, four questions for computational thinking method, and five questions for computational thinking ability.

In order to ensure the questionnaire is scientific and rigorous, we tested reliability and structural validity of the questionnaire: In a small sample (50 valid questionnaires), the Cronbach's $\alpha$ of the questionnaire was 0.714 , which met the reliability requirement. And the Kaiser-Meyer-Olkin value of "KMO and Bartlett's sphere test" was 0.825 , with good structural validity.

\section{Teaching Practices}

\section{Teaching Object and Chapter Selection}

In this study, 112 students of the second year of senior high school affiliated to Renmin University of China were selected for teaching practice. 
This study was carried out with the help of Photoshop design module in The Application of Multimedia Technology in senior high school information technology course. The layers, selection, and dynamic brushes involved in this module contain computational thoughts, such as "decomposition-synthesis and abstraction-modeling", which can be used to cultivate computational thinking.

Three rounds of teaching practice activities were carried out in this study. The first round, use of layers which required students to gradually form and get used to storing complex graphics in different layers, so as to form the idea of "dissociation and synthesis". The second round, use of dynamic brushes which make students gradually form the idea of "abstract-modeling". And the third round, comprehensive work design of cross-section content which consolidated and improved the computational thinking of decomposition, synthesis, abstraction, and modeling dimensions.

Table 3

The Teaching Process of Sub-layer Section

\begin{tabular}{|c|c|c|}
\hline Steps & Teachers' activities & Students' activities \\
\hline 1 & $\begin{array}{l}\text { The teacher presented some images that put everything on one layer and } \\
\text { asked, "What should I do if I want to change the background color of only } \\
\text { part of the image?" }\end{array}$ & $\begin{array}{l}\text { Students thought and tried to solve the } \\
\text { problem, and they found it very difficult to } \\
\text { operate. }\end{array}$ \\
\hline 2 & Teacher introduced the concept of layers and gives examples. & $\begin{array}{l}\text { Students understood the concept and } \\
\text { function of layers and formed the idea of } \\
\text { processing images by layers. }\end{array}$ \\
\hline 3 & $\begin{array}{l}\text { Assignment: Multiple layers are used to store materials to realize the } \\
\text { comparison of the two weather effects of blue sky and haze in the same scene. }\end{array}$ & Thought about the design of the task. \\
\hline 4 & The teacher explained and demonstrated the specific operation steps. & $\begin{array}{l}\text { Through observation, students understood } \\
\text { the thinking mode and method of layered } \\
\text { image processing. }\end{array}$ \\
\hline 5 & $\begin{array}{l}\text { Question: What if the image is very complex and breaks down into layers, } \\
\text { dragging it back and forth from the layers palette is too much of a hassle? }\end{array}$ & $\begin{array}{l}\text { Thought about the problem, and proposed } \\
\text { to create a layer group for easy operation. }\end{array}$ \\
\hline 6 & $\begin{array}{l}\text { Assignment: Please use the photos taken or the images on the Internet as the } \\
\text { materials to design a public poster on anti-haze, calling on people to pay } \\
\text { attention to air pollution. }\end{array}$ & Defined the task theme. \\
\hline 7 & $\begin{array}{l}\text { Specific requirements of the assignment: } \\
\text { (1) The number of pictures and other materials used in the work shall not be } \\
\text { less than eight. } \\
\text { (2) The work shall be stored in Photoshop document (PSD) format, and the } \\
\text { layers in operation shall be retained. Moreover, the layers shall not be less } \\
\text { than five layers. } \\
\text { (3) Document the design idea and process of the work and upload it to the } \\
\text { moodle platform together with the work files (including source files and } \\
\text { image files). }\end{array}$ & Defined the task, idea, and plan. \\
\hline 8 & $\begin{array}{l}\text { Inspected the design of the student's work, emphasizing breaking down tasks } \\
\text { into multiple sub-tasks, and processing images in layers. }\end{array}$ & Completed the poster design. \\
\hline 9 & $\begin{array}{l}\text { Emphasized the requirements of the work design report: write in Word } \\
\text { format, including the understanding of the theme, the process of poster } \\
\text { production, highlights, shortcomings, problems, and gains, etc. }\end{array}$ & $\begin{array}{l}\text { Defined and improved the work design } \\
\text { report. }\end{array}$ \\
\hline 10 & $\begin{array}{l}\text { Selected the representative works, first asked the author of the work to explain } \\
\text { the presentation, then students and teachers to comment. }\end{array}$ & $\begin{array}{l}\text { Appreciated and commented on the works } \\
\text { displayed by other students; and then } \\
\text { further optimized their work. }\end{array}$ \\
\hline
\end{tabular}

\section{The First Round of Teaching Practice}

The first round of teaching activity was about the layered operation in Photoshop (PS). The computational thinking was mainly decomposition and synthesis, and the final task of the design was to design the theme 
works of "anti-haze public welfare posters". What students should master included the concept of layers, creation, deletion, naming, and grouping, as well as the design and modification of complex images. Teachers should develop the computational thinking consciousness of image decomposition and comprehensive, the computational thinking method for the correct decomposition, design, and layout of complex target images, and the computational thinking ability to complete complex image design under the guidance of correct and efficient logical thinking. Detailed teaching process design is shown in Table 3.

It is very important to decompose the complex problem into several easy to operate specific problems and try to implement them in the computer. In this teaching process, teachers should reflect how the whole comprehensive task is decomposed into several small tasks, and in the task decomposition, follow the "top-down, decompose step by step, from complex to simple" way.

\section{The Second Round of Teaching Practice}

In the second round of teaching practice, the teacher taught the dynamic brush in PS, in which the computational thinking was mainly abstract and modeling. Students should be familiar with brush panel, master basic properties, such as brush shape, size, and hardness, and advanced properties, such as shape dynamics and color dynamics. And what the teachers should cultivate was the computational thinking consciousness from concrete to abstract to concrete, the computational thinking method of the abstract, modeling and concrete application, and the computational thinking ability of analyzing and solving concrete problems. Finally, students finished the theme work of "I love Tiananmen Square in Beijing". The detailed teaching process is outlined.

\section{The Third Round of Teaching Practice}

In the third round of teaching practice, it was the design of a comprehensive task completed on the basis of the previous two rounds of teaching practice. In this teaching practice, students should be able to use multiple layers to achieve the task decomposition, use the brush, deformation, etc. to achieve the abstraction and specification of words or scenes, and according to their own ideas and themes, to realize the integral design of the works. In addition, they should clearly show their own design ideas and processes in the whole process, and show the formation process of thinking, such as task decomposition, analysis and synthesis, abstraction and modeling, and design. Finally, students finished the theme work of "My idol". The detailed teaching process is outlined.

\section{Organization of Teaching Practice}

All the three rounds of teaching practice are organized in accordance with the project learning method, and all kinds of learning activities are carried out by a five-member project team.

In order to ensure the quality of teaching, not only can achieve the training goal of subject knowledge, but also can achieve the training requirements of computational thinking development, this study requires each project team must be serious and records the formation process of group work, not only to write down each group member's contribution to the work process, but also pay attention to the repetition, questioning, and iteration during the formation of the work.

To ensure the rigor of research and master the changes in students' computational thinking, all the students were tested before and after using the "questionnaire on the development level of computational thinking of middle school students" in this study. 


\section{Data Analysis and Discussion}

\section{The Results and Problems of the First Round of Teaching Practice}

In terms of teaching evaluation. From the quality of multimedia works, as shown in Table 4, we can see that the quality of the work is not very ideal. Sixty-two point five percent of students scored below 70 and $94.64 \%$ below 80 .

Work performance is not high mainly reflected in the quality of the poster itself is not high, such as colour collocation is improper, the picture is not harmonious, the creative is not high, works design report briefly reflect the design process, etc.

Table 4

The Scores of "Anti-Haze Public Welfare Posters"

\begin{tabular}{llllll}
\hline Score & Below 60 & $60-70$ & $70-80$ & $80-90$ & $90-100$ \\
\hline Number & 14 & 56 & 36 & 4 & 2 \\
Percentage (\%) & 12.5 & 50 & 32.14 & 3.57 & 1.79 \\
\hline
\end{tabular}

From the perspective of multimedia design reports, most of the students' works fit the theme, with different perspectives and different forms. And in the production process, it basically embodies the process of understanding the task, implementing the task decomposition step by step, and designing and completing it step by step. At the same time, in the face of complex images, quite a number of students could not implement the layer separation operation. At first, they did not realize the importance of task decomposition and image slices, until the time of the modified local content found that operation was very complex, at this point to the importance of "decomposition and comprehensive" had the further understanding.

In terms of existing problems. First of all, most students spend too little time filling out design reports. Students get a task, they will be plunged into actual production, rather than a serious and careful planning. Due to the lack of systematic and detailed design, their work lacks the overall design sense and modifiability. Some students do not pay enough attention to the design report and do not think it is helpful to record their thinking and production process. Some of the students' design reports are made overnight after the work was finished and before the work was submitted. The second, in the process of task realization, teachers and students pay too much attention to the work itself and ignore the formation of students' thinking. In front of the teaching practice, we love been communicating with teachers that we should fully reflects students' subjectivity and pay attention to the thinking process of the realization of works. However, teachers are accustomed to the traditional instructional teaching method, and they cannot really let students experience the design process.

\section{The Results and Problems of the Second Round of Teaching Practice}

In terms of teaching improvement. For students who get tasks but do not design and plan carefully, the teacher will inform the students of the evaluation criteria and rules of the work before releasing the task, and emphasize the value and importance of the report. In the process of completing the task, teachers will also urge them to record the design ideas and process of the work.

In the case of teachers paying too much attention to students, teachers need to pay attention to giving students space to think and try, inspire students to try and explore boldly, and encourage them to use all kinds of methods to solve problems. In a word, teachers should carry out the teaching process of students' thinking activities. 
In terms of teaching evaluation. From the quality of multimedia works, as shown in Table 5, we can see that compared to the first round of teaching practice, the number of students who scored under 70 decreased by nearly $50 \%$, scores were mainly concentrated on 70-90 points, and the number of students with more than 90 points has increased somewhat.

From the perspective of multimedia design reports, about $80 \%$ of the students were able to complete the design report as required by the teacher. Analysis of the students' design reports reveals that most students have a clear understanding of how their work was formed. From the determination of physical models, to the derivation of abstract shapes based on models, to the drawing of specific patterns with different colors and shapes by using the generated abstract models, the students showed the process of thinking from concrete to abstract to concrete, and realized the cultivation of computational thinking, such as abstraction, modeling, and design.

Table 5

The Scores of "I Love Tiananmen Square in Beijing"

\begin{tabular}{llllll}
\hline Score & Below 60 & $60-70$ & $70-80$ & $80-90$ & $90-100$ \\
\hline Number & 4 & 12 & 38 & 38 & 20 \\
Percentage (\%) & 3.57 & 10.71 & 33.93 & 33.93 & 17.86 \\
\hline
\end{tabular}

In terms of existing problems. First of all, students have a solid grasp of skills and operational knowledge, but their understanding of the learning objective of this course in computational thinking is not very clear. Some students cannot make a comprehensive self-evaluation against the learning goals after completing the design task. The second, judging from the quality of the work report, the quality of the work report of most students has improved greatly. Some students with weak foundation reported that when facing more difficult or complex knowledge points or tasks, they still have many difficulties in the design process, which is quite difficult and backward.

\section{The Results and Problems of the Third Round of Teaching Practice}

In terms of teaching improvement. In view of students' unclear understanding of learning objectives of computational thinking, teachers explicitly include the cultivation of computational thinking into the classroom teaching objectives, and clearly inform students of the learning goals they need to achieve before the course begins. In this way, in the practice of designing works, students can reflect and evaluate their learning process and learning methods against learning objectives at any time, and independently construct a learning mode based on computational thinking.

In view of the student foundation is weak, teachers emphasize the importance of collaboration and mutual assistance among project members. The project team is not only to assign tasks to individuals, but also to show the spirit of cooperation and to help each other in the process of completing the work. By helping others, your own knowledge can also have a better absorption and internalization effect.

Table 6

The Scores of "My Idol"

\begin{tabular}{llllll}
\hline Score & Below 60 & $60-70$ & $70-80$ & $80-90$ & $90-100$ \\
\hline Number & 0 & 0 & 15 & 43 & 54 \\
Percentage (\%) & 0.00 & 0.00 & 13.39 & 38.39 & 48.21 \\
\hline
\end{tabular}


In terms of teaching evaluation. From the quality of multimedia works, as shown in Table 6, we can see that compared with the second round of teaching practice, the number of students with less than 80 points dropped sharply, and the number of students with more than 90 points increased sharply. Moreover, students' scores are mainly concentrated in $80-100$ districts, accounting for nearly $87 \%$ of the total, indicating that the majority of students have a significant improvement in the quality of their works.

From the perspective of multimedia design reports, the design report of the work is becoming more standardized and detailed, and gradually focuses on the formation of design concepts and ideas, and the writing of operational planning and implementation process is becoming clear. Students have become accustomed to recording their entire design process with the work design report, and have truly realized the standardized thinking activities to guide the design.

\section{The Development and Change of Students' Computational Thinking}

The development of computational thinking from the perspective of work design report. In the course of three rounds of teaching practice, students' design reports are increasingly standardized and improved. For students themselves, the design and production process of their works is clearer and the completion of task is more efficient. Not only in the course, but also in the life of problems and tasks, they can also be more organized and clear completion. For teachers, while pointing out problems in students' design reports, they are also changing students' thinking logic. What teachers should pay attention to is not only the final work, but the process of its design which truly realizes the teaching of computational thinking?

The development of computational thinking from the perspective of the questionnaire survey data. Based on the data collected from the "middle school students' computational thinking development level questionnaire", we carries out Chi-square test for each problem measured before and after (the Chi-square test is used because the original data is ordered data with low discrimination), and the analysis results are shown in Table 7. We can see that on the vast majority of problems in the dimension of computational thinking consciousness, method, and ability, there are significant differences in the data measured before and after. This indicates that this study is effective in improving students' computational thinking from the perspective of design. And from the perspective of option proportion, students' computational thinking consciousness, method, and ability all have a positive improvement.

Table 7

The Results of the Questionnaire

\begin{tabular}{|c|c|c|c|c|c|}
\hline \multirow[b]{2}{*}{ Number } & \multicolumn{5}{|c|}{ Computational thinking consciousness } \\
\hline & A 1 & A 2 & A 3 & A 4 & A 5 \\
\hline \multirow[t]{2}{*}{ Sig value } & 0.000 & 0.001 & 0.004 & 0.001 & 0.000 \\
\hline & \multicolumn{5}{|c|}{ Computational thinking method } \\
\hline Number & B 1 & B 2 & B 3 & B 4 & \\
\hline \multirow[t]{2}{*}{ Sig value } & 0.000 & 0.035 & 0.000 & 0.000 & \\
\hline & \multicolumn{5}{|c|}{ Computational thinking ability } \\
\hline Number & $\mathrm{C} 1$ & $\mathrm{C} 2$ & C 3 & $\mathrm{C} 4$ & C 5 \\
\hline Sig value & 0.000 & 0.650 & 0.000 & 0.225 & 0.014 \\
\hline
\end{tabular}

\section{Conclusion}

The connotation and extension of computational thinking come from computer science. The development 
of computational science is an inevitable trend in the era of big data. "From the computer science to the computer science" is the development and formation of computational thinking must be faced. Therefore, it is feasible to cultivate high school students' computational thinking by taking high school information technology courses as the carrier.

Based on this study, we proposed a teaching model for cultivating students' computational thinking based on information technology courses as shown in Figure 1. Hope to be able to provide reference for peers.

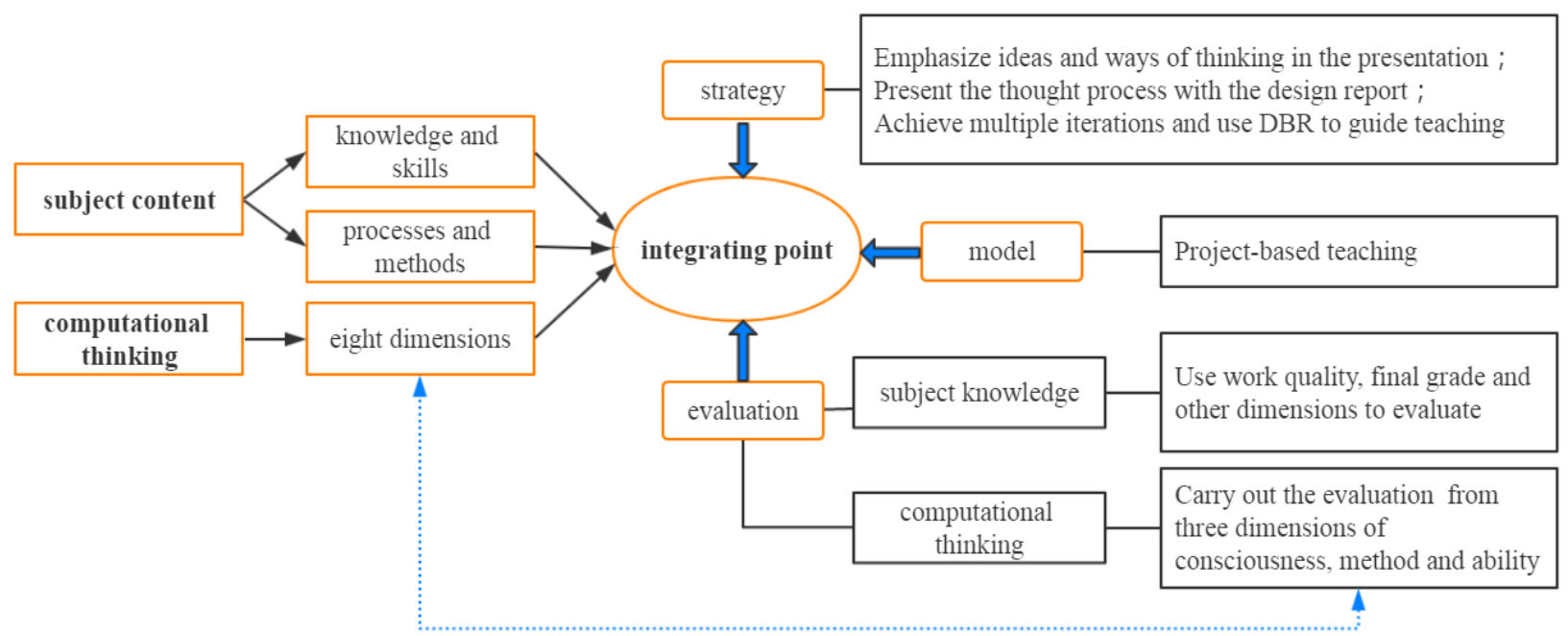

Figure 1. The teaching model of cultivating students' computational thinking based on information technology course.

\section{Reflections and Suggestions}

The reflections and suggestions of the paper are as followings:

1. The connotation and extension of computational thinking are very rich, so the training of high school students' computational thinking must be targeted to avoid general and vague teaching research. When designing the training course of computational thinking based on the specific module of senior high school information technology course, we should pay attention to the integrating point between the connotation of computational thinking and the selected module, so as to bring the cultivation of computational thinking into practice.

2. In the presentation or presentation of high school information technology courses, teachers should pay more attention to the gradual infiltration of logical thinking ability, and the completion of tasks should reflect the concept of students as the main body. The real time, earnest, and standard writing of the work design report plays a very important role in the development of students' computational thinking. Teachers should carefully design the content and format of the work design report, in order to reflect the changes in students' thinking logic and existing problems, so as to timely improve and help them.

3. The cultivation of computational thinking is not an overnight process, but an iterative process of continuous improvement and practice.

\section{References}

Angeli, C., Voogt, J., Fluck, A., Webb, M., Cox, M., Malyn-Smith, J., \& Zagami, J. (2016). A K-6 computational thinking curriculum framework: Implications for teacher knowledge. Journal of Educational Technology \& Society, 19(3), 47-57.

Chen, G. L., \& Dong, R. S. (2011). Computational thinking and college computer basics education. Chinese University Teaching, 15(1), 7-11. 
Chen, P., Huang, R. H., \& Liang, Y. (2018). How to cultivate computational thinking-Based on the research literature of 2006-2016 and the latest international conference papers. Modern Distance Education Research, (1), 98-112.

Li, Y. K., \& Gao, T. G. (2017). Comprehensive interpretation of computational thinking based on thinking perspective. Modern Educational Technology, 27(1), 68-73.

Jiao, J. L. (2008). Design based research: A new orientation of education technology research. Modern Educational Technology, $18(5), 5-11$.

Ma, X. L., Wu, T., \& Liu, L, C. (2015). Computational thinking-The combination of thinking ability training and basic course teaching of information technology. The Chinese Journal of ICT in Education, (2), 22-25.

Mou, Q., Tan, L., \& Zhou, X. J. (2011). Research on the task-based teaching model based on computational thinking. Modern Educational Technology, 21(6), 44-49.

Ren, Y. Q., \& Huang, R. H. (2016). Revised specification for high school information technology curriculum standards. China Educational Technology, (12), 1-3.

Wing, J. M. (2006). Computational thinking. ACM SIGCSE Bulletin, 49(3), 3.

Wing, J. M. (2011). Computational thinking: What and why? [DB/OL] Retrieved September 5, 2017, from https://www.cs.cmu. edu/ Comp-Think/resources/TheLinkWing.pdf

Xie, Z. X. (2017). Thoughts on the entry of computational thinking into information technology education in primary and secondary schools. Primary and Secondary School Information Technology Education, (10), 38-42.

Zhang, X. J., Guo, M. T., \& Li, H. (2015). Analysis of computational thinking in high school information technology courses. E-Education Research, (8), 80-86.

Zhang, W. L., \& Liu, J. S. (2007). Design based research-A new paradigm of education technology research. E-Education Research, (10), 13-17. 